Farum

Sociológico

\section{Forum Sociológico}

Série II

$20 \mid 2010$

A pobreza, pluralidade de olhares e de intervenções

\title{
Ciganos e desigualdades sociais: contributos para a inflexão de políticas públicas de cariz universalista
}

\section{Alexandra Castro}

\section{(2) OpenEdition}

1 Journals

Edição electrónica

URL: https://journals.openedition.org/sociologico/139

DOI: 10.4000/sociologico.139

ISSN: 2182-7427

Editora

CICS.NOVA - Centro Interdisciplinar de Ciências Sociais da Universidade Nova de Lisboa

\section{Edição impressa}

Data de publição: 1 junho 2010

Paginação: 11-19

ISSN: 0872-8380

\section{Refêrencia eletrónica}

Alexandra Castro, «Ciganos e desigualdades sociais: contributos para a inflexão de políticas públicas de cariz universalista», Forum Sociológico [Online], 20 | 2010, posto online no dia 05 setembro 2012, consultado o 29 março 2022. URL: http://journals.openedition.org/sociologico/139 ; DOI: https:// doi.org/10.4000/sociologico.139

Este documento foi criado de forma automática no dia 29 março 2022.

(C) CICS.NOVA 


\title{
Ciganos e desigualdades sociais: contributos para a inflexão de políticas públicas de cariz universalista
}

\author{
Alexandra Castro
}

\section{0 processo de pobreza e exclusão social entre a população cigana: o dilema da diferença?}

1 Reflectir em torno da orientação das políticas públicas para a intervenção com a população cigana parece uma tarefa inglória e ingrata se tivermos em conta a dificuldade em encontrar uma caracterização que considere o perfil diferenciado dos destinatários dessas políticas ou um conhecimento aprofundado e sustentado sobre as causalidades dos processos que conduzem às situações de pobreza e exclusão social e às desigualdades sociais entre esta população.

2 Em Portugal, a falta de uma base sólida de conhecimentos sobre esta matéria é notória e paralela à ausência de visibilidade na agenda das políticas públicas. De facto, não existe nenhum estudo em Portugal de carácter sociográfico que permita uma caracterização pormenorizada da população cigana, apesar de esta ser a minoria étnica a residir há mais tempo no país. Os dados existentes resultam de alguns estudos monográficos que têm sido realizados e permitem apenas aproximações à realidade, como o estudo realizado por F. L. Machado, em 2002, em que a população cigana surge com os níveis de etnicidade mais fortes (Machado, 2002: 41-62).

Os dados mais recentes e de âmbito nacional reportam-se apenas a alguns indicadores, mas evidenciam também a dimensão acentuada dos contrastes sociais da população cigana face à globalidade da população portuguesa, ainda que entre os sectores mais desfavorecidos revelem um fraco peso percentual e para alguns indicadores parece assistir-se a alguma redução do nível dos contrastes sociais. 
4 No quadro do Rendimento Social de Inserção (RSI) a população cigana representa aproximadamente $6,4 \%$ entre os seus beneficiários, valor pouco expressivo no universo dos beneficiários desta medida. Contudo, entre o universo estimado de ciganos portugueses ${ }^{1}$ são mais de metade (52\%), contrastando, assim, com o peso diminuto que o conjunto dos beneficiários desta medida representa no total da população portuguesa (apenas $3,3 \%)^{2}$. No que toca à situação face ao mercado de trabalho, e de acordo com os dados resultantes do inquérito lançado pela $\mathrm{REAPN}^{3}$, em 2009, 84\% dos ciganos entrevistados declararam estar inactivos, destacando-se os desempregados com trabalho informal (45\%). Dos $16 \%$ de indivíduos que constituem a população activa, a grande maioria trabalha por conta própria ou tem negócios familiares (12\%). Também em termos da escolaridade se constata o grande peso de indivíduos com mais de 16 anos sem nenhum nível de escolaridade (33,9\%), ainda que a taxa de analfabetismo para esta faixa etária acompanhe de perto a apresentada para o nível nacional (a rondar ambas os $\left.8 \%^{4}\right)$. No que diz respeito à habitação, verifica-se que entre a população cigana $14,1 \%$ reside em alojamentos não clássicos, representando $7,8 \%$ do total de residentes em alojamentos não clássicos no país ${ }^{5}$. Segundo os dados dos Censos de 2001, apenas $0,8 \%$ do total da população residente em Portugal se encontrava a residir neste tipo de alojamento, revelando, assim, a dimensão da expressividade do contraste social entre as condições de habitação da generalidade da população e a dos ciganos, ainda que entre aqueles que partilham estas condições habitacionais o peso dos ciganos não tenha grande expressividade.

Os dados apresentados, além de revelarem as insuficiências do desenvolvimento da estrutura social portuguesa, evidenciam a situação de maior vulnerabilidade dos ciganos, mas também a heterogeneidade da sua condição social. Se, por um lado, podemos admitir que uma parte significativa dos elementos que integram esta população tem passado por um processo de progressiva fragilização e para o qual não é de descurar o peso exercido pelo "marcador étnico" na produção das desigualdades sociais e nos processos de exclusão social (Guerra et al., 2002), por outro lado, existem já evidências empíricas que permitem compreender o "mistério" enunciado por San Roman sobre as razões de tantos ciganos se integrarem (San Roman, 1986: 194). Os estudos de Maria José Casa-Nova (2002, 2009) e de Olga Magano (2010) são a este título ilustrativos e vão no sentido daquilo que San Roman enfatizava, que para além das diferenças de classe existentes entre os ciganos espanhóis, todos tinham em comum a estratificação étnica (San Roman, 1986: 187).

6 Sem se ter a pretensão de esgotar as causalidades que impedem o movimento das margens para o centro e que tendem a excluir duravelmente uma fatia considerável da população cigana dos sistemas económico, político, sociocultural e geográfico, considera-se que globalmente a condição periférica dos ciganos pode ser traduzida através de dois tipos de distâncias que revelam alguns paradoxos em torno da implementação das políticas sociais de cariz universalista: o pretenso nomadismo e as questões de classe e discriminação cultural entre a população cigana.

\section{O pretenso nomadismo da população cigana}

7 A primeira destas situações reporta-se à distância a que se situam relativamente a uma legitimidade social associada à permanência e à sedentarização num dado território. Este pressuposto conduziu a um triplo posicionamento em torno da mobilidade da 
população cigana - naturalização das identidades, etnicização da exclusão social e transição unívoca para o sedentarismo - que tem marcado, em parte, a produção científica sobre esta matéria e cujos conteúdos vão sendo apropriados e por vezes distorcidos por diversos actores institucionais e políticos (Castro, 2009a). Alguns destes discursos tendem para uma adesão acrítica ao pressuposto de que muitas famílias ciganas não têm acesso a uma casa porque optaram por um modo de vida itinerante, ignorando-se assim as suas dificuldades de acesso a uma habitação condigna e não se entendendo a forma como os próprios ciganos vivenciam um modo de vida pautado pela relação entre itinerância e fixação. Este pressuposto assente em atributos de uma identidade prescrita tende a reflectir as assimetrias do campo social, onde as diferenças são exacerbadas e legitimadas e depois utilizadas como instrumentos de distinção e dominação. As consequências destes procedimentos reflectiram-se, assim, no reforço das distâncias sociais, através das dificuldades associadas a processos de enraizamento territorial, onde as manifestações mais visíveis podem encontrar-se nos dados relativos ao seu realojamento tardio (Lopes, 2008; Santos et al., 2008) ou nos mecanismos institucionais de vigilância e controlo que conduzem à mobilidade forçada de que são alvo (Castro, 2007).

\section{Entre a classe social e a discriminação cultural}

8 A segunda distância resulta da proximidade física com outros grupos sociais decorrente da presença mais massiva nas escolas e nos equipamentos de saúde, mas também nos bairros de habitação social. Esta maior visibilidade das diferenças no domínio público foi acompanhada de um processo de etiquetagem generalizada e simplificadora de determinadas características de alguns elementos da população cigana, onde a situação de precariedade raramente fica confinada à sua posição de classe, mas a sua etnicidade e as discriminações que daqui decorrem exacerbam as suas diferenças sociais. As conclusões de algumas das nossas pesquisas revelaram que a representação dos ciganos como a alteridade radical implicava um processo de etnicização da diferença e de reificação da imagem do grupo, como se aos ciganos apenas se concedesse uma existência grupal e nunca individual e cuja natureza essencial e estruturadora desta pertença estava na base da persistência de imagens sombrias e de medo associadas à sua presença (Duarte et al., 2005a, 2005b).

Em Portugal, ao longo da história da presença dos ciganos assistiu-se ao desenvolvimento de estratégias de luta contra a alteridade sem que, no entanto, se conseguisse alcançar o tão desejado processo de assimilação. O que se verificou foi " $a$ extraordinária resistência das minorias à pressão das maiorias" com consequências nos processos de percepção sobre as causalidades associadas às situações de pobreza e exclusão social e reforçando a identidade e a autonomia da minoria, que se representa como grupo ameaçado e estrangeiro face a um grupo hegemónico e ameaçador, em que qualquer compromisso e concessão é uma ameaça à sua existência (Moscovici e Perez, 1999:119).

10 O "dilema da diferença" não é, pois um "problema acidental", como bem sublinha Minow. Também Touraine, não se referindo explicitamente à população cigana, salienta que, como o trabalho de homogeneização e de racionalização não podia ser conseguido totalmente, foi completado pela inferiorização de todas as categorias que não podiam ser identificadas com o triunfo da razão (Touraine, 1997: 297). E o dilema vai então 
aumentando de proporções à medida que são atribuídas categorias aos indivíduos e se determina quem é de incluir ou de excluir (Minow, 1990: 22). Constata-se deste modo que o insucesso na erradicação da história social dos ciganos teve assim efeitos nos termos utilizados para os designar, sendo a atribuição de "nómadas" uma das faces mais visíveis da tendência para invisibilizar ou expulsar do território local, ou mesmo nacional, uma presença exterior móvel, aparentemente não legítima e desviante face às normas socialmente admitidas.

\section{Políticas sociais e intervenção local reféns de preconceitos e estereótipos?}

11 Em ambas as distâncias acima identificadas um traço comum emerge: a leitura etnicizante da cultura dos pobres incide na assumpção de que a responsabilidade dos problemas está nos indivíduos, relegando-se para um plano secundário o papel que o tipo de recursos e de políticas sociais, e a forma como são mobilizados, podem ter na (re)produção das situações de exclusão social. Mas se a culpa está tendencialmente nos pobres, ou seja, se a estratificação com base em desigualdades estruturais é inexistente ou relegada para um segundo plano, então as respostas dificilmente se distanciam da hostilidade ou da designação dos ciganos pobres como "resistentes à mudança" e como "não se querendo integrar".

12 Vitale, reportando-se à situação dos ciganos em Itália, refere que esta hostilidade se caracteriza por mobilizações muito localizadas, assentes em acções colectivas, organizadas por "empreendedores" que levantam problemas locais e os tornam públicos. Como consequência produz-se um efeito generativo muito forte, quer sobre as dinâmicas da opinião pública, a partir da qual se reforçam os estereótipos, quer sobre as modalidades de selecção ou de implementação de medidas e programas, quer ainda sobre as formas de complementaridade das políticas sociais (Vitale, 2009: 66-69).

13 Esta situação está também presente em muitos concelhos de Portugal. Ao longo dos vários trabalhos de terreno realizados foi possível identificar os principais traços que tendem a caracterizar este tipo de processos a nível local e que podem resumir-se em torno do sistema de acção que enquadra as práticas de actores locais, a três níveis:

- Práticas sociais marcadas pelo anticiganismo que impedem o aceso a políticas públicas de cariz universalista relativamente avançadas ("aqui não damos RSI a ciganos") ou mobilizam fundos públicos para "convidar" os ciganos a abandonarem o concelho, deslocalizando-se e agravando-se o problema (“1000医 por família ou o realojamento no bairro Y?"), ou que deliberadamente não se candidatam a programas existentes para não dar visibilidade à problemática ("distancio-me para que o problema se vá resolvendo por si próprio");

- Práticas profissionais ligadas à intervenção social que tendem para o processamento burocrático das medidas e programas sociais, em detrimento do aprofundamento do conhecimento das famílias, das suas necessidades, competências e expectativas do futuro. Como resultado, a intervenção tende a seguir mais a lógica dos recursos disponíveis e não tanto as necessidades sentidas e expressas pelas pessoas, onde as acções de inserção surgem desajustadas ao perfil dos beneficiários e muitas vezes contraproducentes face às lógicas de funcionamento das famílias;

- Práticas institucionais marcadas pelo fechamento sobre si próprias que impedem a promoção de dinâmicas de parceria e comprometem a mobilização concertada dos recursos disponíveis a nível local ou desvirtuam a filosofia de determinadas medidas. 
14 Todos estes sinais revelam as carências actuais do(s) modelo(s) de integração proposto(s) e do perfil de políticas sociais em vigor, evidenciando: a ocultação do pluralismo de valores e de modos de vida nas sociedades contemporâneas; a inexistência de uma leitura científica dos problemas e de uma avaliação mais sistemática dos indicadores de evolução da situação em que se pretende intervir; as contradições na mobilização dos recursos existentes e nas modalidades que assume a administração de determinadas medidas, programas e projectos. Impõe-se, assim, que se abra um debate construtivo e uma reflexão aprofundada que parta da diversidade do real, onde a diferença cultural deve ser analisada tal como ela é e não pela representação que se faz dela, seja por excesso, diabolizando-a, seja por defeito, ignorando-a (Wieviorka, 1997a: 7). É, pois, altura de questionar de que forma a sociedade portuguesa está disposta a fazer coexistir grupos que testemunham diferentes práticas culturais e modos de vida, aceitando garantir-lhes igualdade de meios e de oportunidades para assegurar a sua continuidade?

\section{Entre a invisibilização política e a configuração de um problema público}

16 Colocar a temática da população cigana nas prioridades da agenda institucional tem sido um processo longo e com contornos diversos face aos diferentes níveis de decisão política: europeu, nacional e local. A longevidade deste processo e o formato que assume naqueles níveis são inseparáveis da forma como determinados problemas sociais se configuram em problemas públicos, pois inerentes a esta configuração encontram-se as modalidades desejadas para o seu tratamento. Ou seja, colocar o tema cigano na arena pública parece pressupor optar por determinado tipo de soluções para os problemas enunciados. As controvérsias em torno desta questão parecem traduzir os dramas políticos de sociedades em que a igualdade e o pluralismo são sua parte integrante e onde a designação e a descrição do problema para o resolver implica um processo de etiquetagem e de actividade colectiva (Minow, 1990; Cefaï, 1996; Dubois, 2009).

17 Encontramo-nos, assim, perante três níveis de análise distintos: i) a alocação da atenção pública sobre a problemática; ii) a modalidade de construção do problema em torno do dilema da diferença; e, iii) as soluções que o desafio da diferença coloca aos poderes públicos.

Relativamente ao primeiro nível de análise enunciado, constata-se que, contrariamente aos problemas sociais, os problemas públicos estão em competição na arena pública e captar a atenção para o tema cigano parece assumir certas especificidades. Como bem refere Vitale, não são as características internas ao objecto problemático, nem a sua extensão e intensidade sobre a população designada, mas sim as formas como se mobilizam e interagem entre si os actores interessados em dar crédito público ao problema (Vitale, 2009: 72).

19 O segundo nível referenciado traduz-se na diversidade de versões que assume o problema em função da diversidade dos seus modos de construção (Cefaï, 1996: 47). Independentemente do nível de decisão política (mais central ou local) e pensando em alguns países europeus, a temática cigana pode assumir-se como um "problema de 
ordem pública" ou como um problema de privação de recursos e de acesso igualitário ao sistema de oportunidades.

Quando se chega ao terceiro nível de análise entra-se no campo das soluções, que, estando relacionado com a forma como se construiu o problema, assume duas tendências: ou se entra pela versão securizante para combater os problemas de ordem pública, ou se questiona os modelos de integração em curso, abrindo-se a possibilidade à "inovação social" nesse domínio. Na primeira situação, e apesar de se negarem direitos fundamentais, as formas de actuação tendem a contornar a lei e impedem a aplicação de sanções. No segundo caso, e como alertam alguns autores, incrementa-se o debate em torno da necessidade de políticas dirigidas a grupos específicos, sobretudo quando o projecto político parece ameaçado ou a expressão de práticas culturais é potencialmente portadora de dificuldades (cf., entre outros, Santos, 1999; Robert, 2007).

Parte-se, assim, para a discussão de dois modos de conceber os processos de integração que desde os anos 80 têm liderado os debates. Um, assente no princípio da universalidade da cidadania, vê os problemas de integração decorrentes de fragilidades económicas e sociais secundarizando a dimensão étnico-cultural. Como efeito perverso desta posição tendem a desenvolver-se políticas de inserção que promovem a assimilação. $O$ outro posicionamento, assente no duplo reconhecimento da igualdade cívica e da diversidade cultural, defende que a inserção social implica o respeito das particularidades étnico-culturais. Esta atitude expressa-se no desenvolvimento de políticas multiculturais que, quando levadas ao extremo, podem desembocar numa espécie de diferencialismo estigmatizante (Schnapper, 1998).

Alguns autores têm, no entanto, demonstrado que extremar os posicionamentos leva a uma escolha artificial e injusta face à forma como se transforma a sociedade e a cultura, pois, como refere Guerra, "cada pólo comporta as suas contradições e parece incapaz de construir uma sociedade em interaç̧ão entre iguais, portanto, democrática" (Guerra, 2008: 104). Trata-se de aprender ou reaprender a combiná-los (Wieviorka, 1997b: 43), sobretudo no caso português, em que a ausência de um modelo claro tende para um pragmatismo que se esforça por inventar respostas inovadoras (Wieviorka, 2008: 234), mas essencialmente quando a experiência política da etnicidade incide nos imigrantes. Este processo poderia passar por envolver o sistema político no debate em torno do multiculturalismo; eliminar a pretensão de universalidade de uma cultura; encontrar os elementos de unidade entre as várias culturas e promover formas criativas de conjugar a diferença com trocas económicas e culturais. Surge aqui um dos dilemas que se colocam aos decisores políticos: como colmatar o passado de discriminação baseado nas diferenças sem legitimar mais as diferenças? Como apresentar a solução para um problema com base em categorias, utilizando-se as mesmas categorias? Várias dificuldades emergem perante o projecto de abertura democrática à diferença, sobretudo para não se reiterar a diferença, quando esta carrega o estigma e se opõe a igualdade (Minow, 1990).

Não se advoga o reconhecimento de um estatuto particular para a população cigana, pois admite-se que esta fórmula coloca as famílias numa alteridade definitiva que reforça, a longo prazo, o seu isolamento, traduzido por um fechamento no pólo da identidade cultural como a única garantia de assegurar a manutenção ou reprodução do grupo e repercutindo-se numa inadaptação crescente à mudança. $O$ fechamento dos ciganos no pólo da identidade cultural, em detrimento da sua participação na vida e económica e social e na sua capacitação para serem actores da sua própria vida, pode 
explicar-se por ser a única via, ou a via mais fácil, de construção da identidade pessoal, sobretudo para aqueles que não se podem definir por aquilo que fazem.

Trata-se, pois, como bem reconheceu Ana S. Marques, de assumir a existência de diferenças sociais e culturais e de "defender um entendimento mais alargado da noção de integração social que não associe a pertença a uma sociedade a um modelo salarial de inserção social" (Marques, 2005: 87), sobretudo quando se adopta uma leitura da noção de exclusão, dificilmente aplicável à população cigana, traduzida no acesso ao rendimento por via do emprego e colocando a tónica na crise das solidariedades informais (idem: 79-80). 0 mesmo é dizer que não se pode associar a noção de integração à subordinação daquelas diferenças a um grupo social e cultural maioritário, mas ela tem de ser encarada como um processo horizontal, não isento de conflito, de influências recíprocas entre todos os grupos sociais (Casa-Nova, 2002: 41).

Perante a constatação destas diversidades socioculturais, torná-las politicamente significativas exige, tal como referia Martuccelli, que se deixe de pensar a igualdade no interior de uma concepção global de injustiça que reenvia a uma situação estrutural de dominação e de exploração, para se passar para uma concepção de justiça social enquanto igualdade de oportunidades. Trata-se de assegurar uma participação igualitária no seio da competição social e de reter a noção de equidade que reconhece a pertinência política das especificidades culturais dos indivíduos, aceitando a ideia de um tratamento diferencial dos membros destas colectividades, a partir do conhecimento da sua situação e dos contextos e processos que produzem as desigualdades. A fonte desta inflexão no sentido da matriz democrática reside no desenvolvimento de um saber social sobre as razões das desigualdades e sobre os resultados das políticas sociais igualitárias (Martuccelli, 1997: 65) e das medidas de discriminação positiva.

O balanço das políticas de discriminação positiva em Portugal parece estar por fazer. Noutros países, o seu balanço não é totalmente negativo, pois tem o imenso mérito de colocar a questão do esforço necessário para fazer recuar a segregação ou a discriminação (Wieviorka, 1997b: 42). Para Wuhl (2008) os argumentos em torno do risco de efeitos perversos de políticas de discriminação positiva (beneficiários como vítimas ou subsídio-dependentes) não se dirigem ao princípio que lhe está subjacente, mas a uma das suas modalidades de aplicação: orientação das políticas sobre grupos específicos sem a articulação com políticas globais. Sendo os efeitos geralmente invocados transversais a qualquer discussão sobre políticas sociais, o autor considera necessário promover debates sobre a interpretação dos resultados em função de critérios partilhados de justiça social.

Se no plano da equidade e da igualdade se apela para o debate, também em torno do plano das liberdades fundamentais se vai no mesmo sentido, sobretudo por ser extremamente difícil definir o que vai para além daquilo que é livremente aceite no interior de determinado grupo sociocultural e o que é contrário às liberdades fundamentais. Como refere Touraine, esta constatação conduz à conclusão de que a fronteira entre a diversidade aceite e o crime punido não é estabelecida naturalmente nem de maneira permanente, mas decorre de um debate público (Touraine, 1997: 305).

Se, como refere Martuccelli, o acordo parece imediato entre o princípio da equidade (melhor dirigir as políticas públicas) e o princípio da diferença (ter em conta as especificidades das minorias), o que parece estar no centro do desacordo é a "natureza" das reivindicações identitárias, marcadas pelo seu carácter reactivo por referência a 
uma alteridade cada vez mais de carácter dominante (Martucceli, 1997: 79). No entanto, a história da presença dos ciganos em Portugal de mais de 500 anos revela nunca terem lutado pelo seu reconhecimento institucional, nem nunca terem competido com outros interesses (Magano, 2006), não parecendo, assim, que a coesão social possa ficar afectada com projectos políticos que valorizem a diferença.

\section{A orientação explícita, mas não exclusiva das políticas sociais: a construção de um caminho em Portugal?}

Nos últimos anos assistiu-se, a nível internacional e europeu, a um envolvimento institucional e político, sem precedentes, em torno da temática da população cigana, a que não será alheio o crescimento das desigualdades e da fragmentação social e o aumento dos fluxos migratórios numa Europa que se quer (ou queria) sem fronteiras. Se, como se constatou, a manifestação daquelas desigualdades encerra em si alguns contornos étnicos, parece ainda estar por fazer uma avaliação rigorosa destas situações. No contexto europeu, paralelamente às várias resoluções do Parlamento Europeu ${ }^{7}$, o Conselho da Europa inclui a temática na sua agenda e a Comissão desenvolveu uma série de medidas e um conjunto de mecanismos institucionais, importando referir as iniciativas mais recentes, nomeadamente a criação em 2008 da Plataforma Integrada para a Inclusão dos Ciganos $^{8}$, assente num mecanismo de cooperação entre os EstadosMembros, actores da sociedade civil e de instituições europeias com o objectivo de apoiar iniciativas, a troca de experiências, e promover uma maior compreensão sobre a temática.

No seio desta plataforma foram estabelecidos, em Abril de 2009, os "10 Princípios Básicos para a Inclusão dos Ciganos", no sentido de se ter orientações claras na forma de abordar o tema cigano através de políticas e recursos. Alguns dos critérios adoptados surgem como uma novidade no tratamento do tema a nível europeu, nomeadamente os princípios que enunciam a aposta em medidas explícitas, mas não exclusivas ${ }^{10}$, no enfoque intercultural e na normalização e transversalidade.

31 Já no início de Setembro de 2010, na sequência dos acontecimentos ocorridos em França em torno da expulsão de ciganos do território nacional, mas também decorrente da Comunicação da Comissão de 7 de Abril ${ }^{11}$, que apelava à adopção de programas concretos para contribuir para a integração dos ciganos, cria-se a Roma Task Force para avaliar a utilização dada pelos Estados-Membros aos fundos da União Europeia e as formas de reforçar a sua eficácia. Ainda no âmbito desta Comunicação, e reconhecendose a heterogeneidade da população cigana entre países e em função dos seus contextos de residência, salienta-se a dificuldade da adopção de uma estratégia única, o que não impede que se elaborem modelos diferenciados em função dos contextos geográfico, económico, social, cultural e jurídico. Avança-se, assim, com uma divisão em grandes tipos de comunidades ciganas vulneráveis, em função dos seus contextos residenciais, das formas de coexistência, do grau de mobilidade e da nacionalidade ou não de um Estado-Membro. A Estratégia EU 2020, bem como o novo ciclo de financiamentos, são, assim, enunciados como podendo trazer soluções específicas aos problemas de diferentes tipos de comunidades ciganas. Assim, em Abril de 2011, a Comissão Europeia apresenta a estratégia a favor da integração dos ciganos, adoptada pelo Conselho Europeu a 24 de Junho, introduzindo normas vinculativas para garantir que a 
população cigana tenha um verdadeiro acesso à educação, ao emprego, à habitação $\mathrm{e}$ aos cuidados de saúde ${ }^{12}$.

Todos os desenvolvimentos acima descritos tendem para uma abstracção da historicidade inerente à complexa diversidade de situações locais, parecendo alimentar a ideia de uma minoria massivamente marginalizada, homogénea e dificilmente integrável, levando Olivera (2011) a questionar se a luta contra as discriminações ou invocar a "inclusão" são as acções certas, quando parece ser a forma como o sistema funciona que produz os seus marginais e etniciza a pobreza.

No quadro de um ambiente político claramente neoliberal, onde, comparativamente com o que se passa em vários Estados-Membros, parece aparentemente mais fácil definir o problema e a sua solução, vem assim colocar-se o dedo na ferida de muitos países que até agora pareciam preferir uma abordagem do tipo laisser-faire em detrimento de uma coordenação eficaz de esforços a diferentes níveis da acção política. Temos de esperar para ver que tipo de repercussões esta europeização da temática cigana vem trazer a Portugal, pois se o conhecimento, como constatámos, é pouco sustentado, ao nível da forma como se coloca nas prioridades da agenda institucional apresenta lacunas e impasses que importa, de forma sucinta, apresentar.

No quadro das quatro gerações de Planos Nacionais de Aç̧ão para a Inclusão (2001-2010) as medidas delineadas em torno da população cigana foram escassas, pontuais ou inexistentes, e no caso do último PNAI, terminado em 2010, não se criaram as condições para o cumprimento de algumas das medidas enunciadas. De referir, no entanto, que alguns avanços se registaram face ao PNAI de 2006-2008, que foi totalmente omisso em termos de medidas e metas a alcançar com esta população (Castro, 2007: 80).

O reconhecimento, em 2008, da necessidade de "adoptar medidas adicionais, especialmente dirigidas para as comunidades ciganas (...)", não parece ter sido um processo pacífico, exigindo uma mobilização por parte de alguns actores sociais. Situação que não é de espantar quando o Estado português declina um convite endereçado pela Década para a Inclusão dos Ciganos (2005-2015) ${ }^{13}$, admitindo que a nível nacional já existe uma estratégia.

Mas mesmo não existindo uma estratégia explícita, ao contrário do que existe por exemplo para os imigrantes, interessa, no entanto, questionar a relevância de alguns instrumentos, nomeadamente do PNAI, por ter sido o único documento oficial de âmbito nacional onde se menciona a população cigana: Qual a importância assumida por este "instrumento de planeamento de coordenação estratégica e operacional das políticas que permitem prevenir e combater as situações de pobreza e exclusão"? Como garantir o compromisso no cumprimento das metas estabelecidas e a monitorização mais adequada?

À partida, a existência destes instrumentos de planeamento estratégico, traduzidos em medidas concretas de intervenção, permitiria estabilizar formas de acção colectiva e tornar mais previsíveis, e visíveis, os comportamentos dos actores, pois na sequência das medidas accionadas passariam a ter capacidades muito diferenciadas de acção. No entanto, a história das políticas públicas em Portugal tem demonstrado alguma resistência à adopção de medidas diferencialistas dirigidas a grupos socioculturais específicos. Excepção deve ser feita a alguns projectos de âmbito local - como o Projecto Mediadores Municipais, preferencialmente dirigido a ciganos (Castro e Santos, 2010) -, mas também ao Programa Escolhas. No entanto, vários dispositivos públicos 
estão já implicitamente destinados a determinadas categorias de população, parecendo assim que a realidade prática das políticas públicas está mais aberta à diferença cultural do que assumidamente parece dar a entender. Pensando em alguns destes dispositivos em vigor (Contratos Locais de Desenvolvimento Social, Territórios Educativos de Intervenção Prioritária...), constata-se uma tendência para se visar os territórios - dotálos de uma capacidade diferenciada de acção - em detrimento de determinadas categorias sociais.

Favorecer ou obstaculizar as condições de reconhecimento de determinados grupos (Pizzorno, 2007, cit. por Vitale, 2009: 67) e proporcionar (ou não) igualdade de oportunidades no acesso a bens e serviços ficam, assim, na dependência da forma como se mobilizam estes instrumentos a nível local. Deverá questionar-se, então, como este princípio de participação igualitária é acompanhado da noção de equidade que pressupõe um tratamento diferencial em função de especificidades culturais, quando se sabe que muitos profissionais não estão treinados para trabalhar com a diferença, o que se reflecte, por exemplo, nas formas de organização do trabalho pedagógico na sala de aula e no baixo grau de proximidade e de confiança entre pais e professores, que pouco incentivam a uma frequência regular do sistema de ensino (Casa-Nova, 2008), mas também em padrões segregativos do ponto de vista sócio-urbanístico.

A autora deste artigo agradece a Isabel Guerra e Dulce Moura a leitura crítica e construtiva de uma primeira versão deste texto

\section{BIBLIOGRAFIA}

BRANCO, F. (2003), "Os ciganos e o RMG: direitos sociais e direito à diferença”, Intervenção Social, 27, pp. 121-143.

CASA-NOVA, M. J. (2002), Etnicidade, género e escolaridade - estudo em torno das socializações familiares de género numa comunidade cigana da cidade do Porto, Lisboa, Instituto de Inovação Educacional.

CASA-NOVA, M. J. (2008), “Tempos e lugares dos ciganos na educação escolar pública”, in CasaNova, M. J. e P. Palmeira (Coords.) Minorias, Lisboa, Ministério do Trabalho e da Solidariedade Social, pp. 7-55.

CASA-NOVA, M. J. (2009), Etnografia e produção de conhecimento. Reflexões críticas a partir de uma investigação com ciganos portugueses, Lisboa, Colecção Olhares, 8, ACIME.

CASTRO, A. (2004), "Ciganos e itinerância. Uma aproximação à realidade concelhia e às suas formas de hospitalidade", Cidades, Comunidades e Territórios, 9, pp. 55-69.

CASTRO, A. (2006), Ciganos, Territórios e Itinerância. Análise de um questionário enviado aos postos da Guarda Nacional Republicana, Texto Policopiado, Produto do Projecto "Ciganos e territórios: mobilidade e sedentarização no contexto urbano português”, Lisboa, CET.

CASTRO, A. (2007), "Dos contextos locais à invisibilização política: discussão em torno dos ciclos de exclusão habitacional dos ciganos em Portugal”, Cidades. Comunidades e Territórios, 15, pp. 63-86. 
CASTRO, A. (2009a), “Tsiganes, mobilité et sédentarisme: Quel lieux dans la ville?”, Études tsiganes, 39-40, pp. 112-127.

CASTRO, A. (2009b), “Avaliação das Necessidades dos Municípios na Implementação do Modelo Integrado de Actuação com a População Cigana”, in População Cigana em Situação de Precariedade Habitacional: Avaliação das Necessidades dos Municípios na Implementação do Modelo Integrado, pp. 13-23.

CASTRO, A. e M. Santos (2010), "Na busca de consensos para a promoção da coesão social: o percurso profissional de mediadores municipais ciganos”, Cidades. Comunidades e Territórios, 20-21, pp. 139-154.

CEFAÏ, D. (1996), “La construction des problèmes publics. Définitions de situations dans des arènes publiques", Réseaux, volume 14 (75), pp. 43-66.

COMISSÃO PARLAMENTAR DE ÉTICA, SOCIEDADE E CULTURA (2009), "Relatório das audições efectuadas sobre Portugueses Ciganos no âmbito do Ano Europeu para o Diálogo Intercultural, Subcomissão para a Igualdade de Oportunidades e Família", p. 55.

DUARTE, I. (coord), et al. (2005a), Coexistência inter-étnica, espaços e representações sociais: os ciganos vistos pelos outros, Lisboa, ACIME.

DUARTE, I. (coord.), et al. (2005b), Os ciganos vistos pelos outros: proximidade social em espaços de coexistência interétnica, Lisboa, CET/FCT.

DUBOIS, V. (2009), "L'action publique” in A. Cohen, et al. (eds.), Nouveau manuel de science politique, Paris, Éditions La Découverte.

GUERRA, I., et al. (2002), Avaliação de Impactes do Rendimento Mínimo Garantido - Caracterização do Perfil das Minorias Étnicas, Lisboa, Instituto para o Desenvolvimento Social, Colecção Estudos.

GUERRA, I. (2008), “A cidade multicultural e multiétnica. Gestão da diversidade e procura da democracia", in A. T. Matos e M. F. Lages (coords.), Portugal: percursos de interculturalidade, Lisboa, ACIDI, pp. 97-118.

LOPES, D. S. (2008), Deriva Cigana. Um estudo etnográfico sobre os ciganos de Lisboa, Lisboa, ICS, p. 410.

MACHADO, F. L. (2002), Contrastes e Continuidades. Migração, Etnicidade e Integração dos Guineenses em Portugal, Oeiras, Celta.

MAGANO, O. (2006), “A (re)produção das desigualdades sociais dos ciganos em Portugal”, Actas do First International Conference of Young Urban Researchers (FICYUrb), Lisboa, CIES.

MAGANO, O. (2010), Tracejar vidas normais. Estudo qualitativo sobre a integração social de indivíduos de origem cigana na sociedade portuguesa, Tese de Doutoramento, Universidade Aberta, p. 378.

MARQUES, A. S. (2005), "O trabalho e o acesso ao rendimento entre os ciganos. Virtualidades e limitações das leituras da noção de exclusão social na compreensão da situação dos ciganos”, Cidades. Comunidades e Territórios, 10, pp. 73-89.

MARTUCCELLI, D. (1997), “Les contradictions politiques du multiculturalisme”, in M. Wieviorka (dir.), Une société fragmentée ? Le multiculturalisme en debat, Paris, La Découverte, pp. 61-82.

MINOW, M. (1990), Making All the Difference. Inclusion, Exclusion, and American Law, Ithaca-London, Cornell University Press, p. 159.

MOSCOVICI, S. e J. A. Perez (1999), “A Extraordinária Resistência das Minorias à Pressão das Maiorias" in J. Vala (ed.), Novos Racismos, Lisboa, Celta. 
OLIVERA, M. (2011), “La fabrique experte de la 'question rom': multiculturalisme et néolibéralisme imbriqués”, La Revue Lignes, 34, pp. 104-118.

ROBERT, C. (2007), Éternels étrangers de l'intérieur, Paris, Desclée de Brouwer.

SANTOS, B. S. (1999), "A construção multicultural da igualdade e da diferença", oficina do CES, 135, p. 61.

SAN ROMAN, T. (ed.) (1986), Entre la marginación y el racismo. Reflexiones sobre la vida de los gitanos, Madrid, Alianza Universidad.

SANTOS, M., et al. (2008), "Etnia Cigana nos bairros municipais de Lisboa - recenseamento e reflexões" in Ciganos, Territórios e Habitat, Actas do Seminário, Lisboa, pp. 147-167.

SCHNAPPER, D. (1998), La Relation à l'autre, Paris, Gallimard.

TOURAINE, A. (1997), “Faux et vrais problèmes”, in M. Wieviorka (dir.), Une société fragmentée? Le multiculturalisme en debat, Paris, La Découverte, pp. 291-319.

VICENTE, M. J. (2009), As comunidades ciganas e a saúde: um primeiro retrato nacional, Madrid, Fundación Secretariado Gitano, p. 92.

VITALE, T. (2009), "Sociologia dos conflitos locais contra os Rom e Sinti em Itália. Pluralidade de contextos e variedade de instrumentos políticos", Cidades, Comunidades e Territórios, 19, pp. 65-80.

WIEVIORKA, M. (1997a), "Introduction: Un débat necessaire” in M. Wieviorka (dir.), Une société fragmentée? Le multiculturalisme en debat, Paris, La Découverte, pp. 5-8.

WIEVIORKA, M. (1997b), “Culture, société et démocratie”, in M. Wieviorka (dir.), Une société fragmentée? Le multiculturalisme en debat, Paris, La Découverte, pp. 11-60.

WIEVIORKA, M. (2008), «L'intégration: un concept en difficulté», Cahiers internationaux de sociologie, vol. CXXV, pp. 221-240.

WUHL, S. (2008), “La 'discrimination positive' à la française. Les contradictions des politiques publiques", Informations Sociales, 148, pp. 84-93.

\section{NOTAS}

1. As estimativas sobre a dimensão da população cigana em Portugal, embora incertas e de uma grande variabilidade, apontam para números entre os 30 e 100 mil, retendo-se aqui um universo de 40 mil (cf. Castro, 2004, 2006).

2. De acordo com os dados disponibilizados pelo Instituto da Segurança Social para o "Relatório das audições efectuadas sobre Portugueses Ciganos" (Comissão Parlamentar de Ética, Sociedade e Cultura, 2009: 22-23), existiam em Dezembro de 20085275 famílias ciganas beneficiárias do RSI em Portugal Continental. Estimando-se que a dimensão média da família é de 4 elementos, o número de beneficiários ciganos rondaria os 21?100 indivíduos, num total de 328?919 beneficiários (ISS, 2008: 26).

3. A amostra deste estudo, ainda que apresente as limitações inerentes ao desconhecimento exacto do universo da população cigana portuguesa, logo sendo apenas uma aproximação à realidade, teve o mérito de se constituir pelas seguintes quotas: idade, género, localização rural// urbana, tipologia de habitação (Vicente, 2009).

4. A comparação estabelecida com os dados dos Censos tem de ser relativizada. Por um lado, a taxa de analfabetismo definida pelo INE estabelece os 10 anos de idade como referência para o cálculo desta taxa, ao passo que os dados disponíveis no estudo são para os indivíduos com mais de 16 anos. Considera-se, no entanto, esta comparação mais fidedigna do que aquela que é 
apresentada no estudo, que calcula esta taxa para o total da população residente no continente e que dá um valor de $15 \%$. Por outro lado, o desfasamento temporal da recolha de informação entre os Censos e o questionário lançado pela REAPN poderá fazer que os dados mais actuais para este indicador apresentem uma diminuição.

5. Desde 2006 que tenho vindo a sistematizar a informação sobre a população cigana a residir em alojamentos não clássicos (barracas, casas rudimentares de madeira, improvisadas, móveis), contabilizando em 50 concelhos 6142 indivíduos. As fontes dessa informação foram o trabalho de terreno realizado ao abrigo do projecto financiado pela Fundação para a Ciência e a Tecnologia, um questionário enviado no âmbito do Projecto Equal - Coimbra. Cidade de Todos (Castro, 2009a), uma colaboração para o European Roma Rights Centre, em que se recolheu informação para 14 concelhos do país, e notícias de imprensa.

6. Ver a este propósito as reflexões conduzidas em Portugal e França sobre a aplicação do RSI à população cigana (Branco, 2003: 137-138, Robert, 2007: 232-234).

7. A Resolução de 2008 - Uma Estratégia Europeia relativa à população cigana - é especialmente significativa, pois coloca o destaque na necessidade de liderança europeia em torno da luta contra a discriminação, uma vez que se trata de um problema estrutural que requer um enfoque a nível europeu, bem como a de Setembro de 2010, que reforça a necessidade de ter uma estratégia comum para a população cigana.

8. http://ec.europa.eu/social/main.jsp?catId=761\&langId=en.

9. Estes princípios constituem um anexo às conclusões do Conselho da Europa de 8 de Junho de 2009: http://www.euromanet.eu/upload/21/69/EU_Council_conclusions_on_Roma_inclusion_June_2009.pdf.

10. Cf. a este propósito o recente alargamento da utilização do Fundo Europeu de Desenvolvimento Regional a intervenções na área da habitação a favor de "comunidades marginalizadas" em todos os Estados-Membros, visando, explícita mas não exclusivamente, a população cigana. Aprovado em Fevereiro de 2010, encontra-se disponível em: http:// www.europarl.europa.eu/sides/getDoc.do?pubRef=-//EP//TEXT+TC+P7-TC1-

COD-2009-0105+0+NOT+XML+V0//PT.

11. $\operatorname{COM}(2010) 133$ final, disponível em: http://eur-lex.europa.eu/LexUriServ/LexUriServ.do? uri=COM:2010:0133:FIN:EN:PDF. Ver também "Roma in Europe: The Implementation of European Union Instruments and Policies for Roma Inclusion - Progress Report 2008-2010 - SEC (2010) 400 final, disponível em http://www.statewatch.org/news/2010/apr/eu-com-roma-inclusionsec-400-10.pdf.

12. Trata-se do documento "Um quadro europeu para as estratégias nacionais de integração dos ciganos até 2020", $\operatorname{COM}(2011) 173$ final, Bruxelas, 5.4.2011, disponível em http://eurlex.europa.eu/LexUriServ/LexUriServ.do?uri=COM:2011:0173:FIN:PT:PDF.

13. Esta iniciativa é um compromisso político de vários governos europeus (Albânia, Bósnia e Herzegovina, Bulgária, Croácia, República Checa, Hungria, Macedónia, Montenegro, Roménia, Servia, Eslováquia, Espanha) para promover a inclusão social dos ciganos, sobretudo nos domínios da educação, emprego, saúde e habitação.

\section{RESUMOS}

Este artigo questiona o modelo de integração universalista que tem sido preconizado pelas políticas públicas em Portugal face à constatação da persistência de situações de pobreza e 
exclusão social entre a população cigana. Procura-se, assim, colocar em discussão os problemas actuais daquele modelo e as suas dificuldades em intervir adequadamente face a uma parte considerável das pessoas ciganas, destacando-se os seus contornos polémicos no recente contexto institucional nacional e europeu. Apresentam-se, assim, os equívocos do debate europeu sobre a inserção da população cigana - dividido entre uma generalização abusiva dos traços culturais pretensamente universalistas desta população e a normatividade da "igualdade perante a lei" - e reflecte-se sobre a forma como o modelo de integração universalista defendido em Portugal se tem traduzido paradoxalmente pela invisibilidade da problemática e pela produção de um discurso de culpabilização da população cigana.

This paper questions the universalistic model of integration which has been recommended by public policies in Portugal relating to the persistence of situations of poverty and social exclusion among the Roma population. Thereby, it is aimed to put into discussion the current problems of that model and its difficulties in intervening appropriately over a considerable number of Roma people, highlighting its controversial contours in the recent national and European institutional context. It is presented the mistakes of the European debate on the inclusion of the Roma population - divided between an abusive generalization of the cultural characteristics allegedly universalists of this population and the normativity of "equality by the law" - and reflected on how the universalistic model of integration defended in Portugal has resulted paradoxically by the invisibility of the problematic and by the production of a speech blaming the Roma people.

\section{ÍNDICE}

Keywords: Roma population, social inequalities, public policies, integration models

Palavras-chave: população cigana, desigualdades sociais, políticas públicas, modelos de integração

\section{AUTOR}

\section{ALEXANDRA CASTRO}

Investigadora do DINÂMIA/CET-ISCTE-IUL castro.alexandra@gmail.com 